\title{
Variability in 'Rough Lemon' x 'Sour Orange' Hybrids for Foliar Traits and their In vitro Screening against Phytophthora nicotianae
}

\author{
Gurpreet Rama, Krishan Kumar ${ }^{1 *}$, Anita Arora, Nirmaljit Kaur ${ }^{2}$, H.S. Rattanpal, J.S. \\ Brar, P.K. Arora ${ }^{1}$ and Subhash Chander $^{1}$ \\ Department of Fruit Science, Punjab Agricultural University, Ludhiana141 004, India \\ ${ }^{1}$ Punjab Agricultural University, Dr JC Bakhshi Regional Research Station, Abohar, India \\ ${ }^{2}$ Department of Botany, Punjab Agricultural University, Ludhiana 141 004, India \\ ${ }^{\star}$ E-mail: kkshorti@pau.edu
}

\begin{abstract}
Phytophthora nicotianae, a deadly fungus, causes huge damage to citrus. Developing tolerant rootstocks is an eco-friendly solution to manage it. In this study, we characterized 21 'Jatti khatti' (a strain of 'Rough lemon') × 'Sour orange' hybrids for four leaf traits and determined their tolerance against Phytophthora nicotianae using in vitro leaf inoculation method. For leaf traits, the hybrids displayed a higher magnitude of variation than the parents. The hybrids represented five different leaf lamina shapes, six leaf apex types, three leaf margins and three petiole wing shapes. The appearance of novel leaf variability pointed to the possibility of recombination in parental gametes. In leaf inoculation based screening, the susceptibility to Phytophthora infection was related to the size of lesions on leaf discs. The parents 'Jatti khatti' and 'Sour orange' recorded significantly different sized lesions of 2.6 and $1.3 \mathrm{~cm}$, respectively. The hybrid 83-3 produced significantly smaller lesion size $(1.0 \mathrm{~cm})$ while six other hybrids recorded lesions of size similar to 'Sour orange'. Hence, these seven hybrids can be considered tolerant to Phytophthora and can be further tested for other biotic and abiotic stresses to ultimately find a rootstock that possess most of the desirable features of the two parents.
\end{abstract}

Keywords: Citrus, Rootstock, Hybrids, Phytophthora nicotianae, Tolerance, In vitro leaf inoculation

Rough lemon (Citrus jambhiri Lush.) is the commercial citrus rootstock. It is tolerant to most of the viruses including citrus tristeza virus and induces prolific bearing in the budded scion varieties (Kumar et al 2010). In addition, it has a high degree of polyembryony, which is an important trait for clonal propagation of rootstocks. 'Rough lemon' is highly susceptible to a soil borne fungus Phytophthora nicotianae. The genotypes like Poncirus trifoliata and its hybrids like 'Swingle citrumelo', 'X-639' and 'Sour orange' are the promising sources of resistance to develop rootstock hybrids resistant to Phytophthora (Savita et al 2012, Dhakad et al 2014, Lima et al 2018). Of the above mentioned Phytophthora tolerant genotypes, 'Sour orange' (C. aurantium $L$.) also imparts high quality to the fruits of budded citrus varieties. It also confers tolerance to citrus blight, xyloporosis and exocortis (Castle et al 1993). In order to introgress the Phytophthora tolerance from 'Sour orange', the hybrids were developed in the cross of 'Jatti khatti' (a strain of 'Rough lemon', used as rootstock in Punjab, India) and 'Sour orange' and their hybridity was confirmed through polymorphic SSR markers (Kaur et al 2021). To quickly determine the tolerance of these hybrids to $P$. nicotianae, their rapid screening is required. Leaf inoculation is a rapid and reliable method to determine genotypic reaction to Phytophthora (Vawdrey et al 2005). In citrus, morphological traits hold importance for characterization of genotypes/ accessions and are also required for registration of most of the varieties (Castellana et al 2020). Various leaf types and petiole wings are particularly important for characterization of citrus at young plant stage (Ballve et al 1997). In this study, 21 'Jatti khatti' $\times$ 'Sour orange' hybrids were characterized for leaf based traits and their tolerance to $P$. nicotianae was determined using in vitro leaf inoculation method.

\section{MATERIAL AND METHODS}

Twenty one pre-developed 'Jatti khatti' $\times$ 'Sour orange' hybrids at Dr. J.C. Bakhshi RRS, Abohar were characterized for leaf based traits namely shape of leaf lamina, leaf apex, leaf margin and petiole wing as given in the IPGRI Descriptor for citrus (Anonymous 1999). Apart from it, different leaf variables were scored as 1 or 0 and the genetic relatedness of the parents and hybrids was estimated based on these variables, which was calculated using Jaccard coefficient of association. The cluster analysis was performed through Unweighted Neighbour-Joining Tree method in software package DARwin 6.0 (Perrier and Jacquemoud 2006). The Phytophthora tolerance of these hybrids was determined by leaf inoculation method as described by Dhakad et al (2014). To verify the validity of the method in differentiating the Phytophthora tolerance, alongside hybrids, the parents 'Jatti 
khatti' and 'Sour orange' were also included in the study. Healthy leaves were collected from parents and 21 hybrids. The circular discs were made from the leaves. These leaf discs were surface sterilized with $0.1 \%$ mercuric chloride for 10 seconds followed by washing with sterile double distilled water twice. The surface sterilized leaf discs were then punctured with a sterile needle. The pathogen (Phytophthora nicotianae) culture was obtained and maintained on a selective PARPH-CMA medium at $25 \pm 1^{\circ} \mathrm{C}$. Four days old culture of the pathogen was used for in vitro inoculation of citrus leaf discs. One leaf disc was placed in each petri plate containing inoculum under aseptic conditions. Three replications were kept for each parent and hybrids. The petri plates were incubated at $25 \pm 1^{\circ} \mathrm{C}$. After 48 hours of incubation, the data on lesion size was recorded. The statistical significance of the data was checked using one way analysis of variance (ANOVA) and differences among the genotypic means were determined using Tukey's HSD test in software SAS 9.1.

\section{RESULTS AND DISCUSSION}

Morphological variation: The data on variation of leaf attributes among parents and 21 hybrids is presented in Table 1. The parents 'Jatti khatti' and 'Sour orange' had ovate leaf shapes. The hybrids represented five different leaf shapes in descending order of abundance namely ovate (9), elliptic (5), obovate (4), lanceolate (2), round to orbicular (1) (Table 1, Plate 1). The leaf apex was acute to retuse in 'Jatti khatti' and acuminate in 'Sour orange'. The hybrids represented six different leaf apex types in descending order of frequency i.e. acute (9), acuminate (4), acute to obtuse (3), round to obtuse (3), obtuse to retuse (1), and retuse (1) (Table 1, Plate 2). The parents- 'Jatti khatti' and 'Sour orange' had sinuate leaf margins while hybrids had three different types of margins i.e. sinuate (10), dentate (7) and crenate (4) (Table 1, Plate 3). Petiole wing is one of the important morphological character, which has utility in genotypic identification (Ballve et al 1997). The parents 'Jatti khatti' and 'Sour orange' had linear and obdeltate type of petiole wings. Three different

Table 1. Characterization of parents and 21 hybrids based on leaf shape, leaf apex, leaf margin and petiole wing shape

\begin{tabular}{|c|c|c|c|c|}
\hline \multirow[t]{2}{*}{ Plant ID } & \multicolumn{4}{|c|}{ Leaf attributes } \\
\hline & Leaf shape & Leaf apex & Leaf margins & Petiole wing shape \\
\hline Jatti khatti (q) & Ovate & Acute to retuse & Sinuate & Linear \\
\hline Sour orange $(\widehat{\jmath})$ & Ovate & Acuminate & Sinuate & Obdeltate \\
\hline H52 & Elliptic & Acute & Sinuate & Obdeltate \\
\hline $\mathrm{H} 13-2$ & Elliptic & Acute & Dentate & Obdeltate \\
\hline H120-1804 & Elliptic & Acute & Sinuate & Linear \\
\hline H88-2 & Elliptic & Acute & Dentate & Obdeltate \\
\hline H97-2 & Elliptic & Acuminate & Dentate & Obdeltate \\
\hline $\mathrm{H} 74-1$ & Lanceolate & Acuminate & Sinuate & Obdeltate \\
\hline $\mathrm{H} 78-1$ & Lanceolate & Acuminate & Dentate & Obdeltate \\
\hline $\mathrm{H} 750$ & Obovate & Obtuse to retuse & Crenate & Obdeltate \\
\hline $\mathrm{H} 134-1$ & Obovate & Round to obtuse & Sinuate & Linear \\
\hline H79-2 & Obovate & Retuse & Sinuate & Obdeltate \\
\hline H58 & Ovate & Acute & Sinuate & Linear \\
\hline $\mathrm{H} 76$ & Ovate & Acute to obtuse & Dentate & Obdeltate \\
\hline H558 & Ovate & Round to obtuse & Crenate & Obcordate \\
\hline H575 & Ovate & Acute to obtuse & Crenate & Obcordate \\
\hline H3-1 & Ovate & Acute to obtuse & Sinuate & Linear \\
\hline $\mathrm{H} 255-3$ & Ovate & Acute & Dentate & Linear \\
\hline H307-3 & Ovate & Acute & Crenate & Obdeltate \\
\hline H32-6 & Ovate & Acute & Dentate & Obcordate \\
\hline H83-3 & Ovate & Acuminate & Dentate & Obdeltate \\
\hline H90-1 & Ovate & Acute to obtuse & Sinuate & Linear \\
\hline $\mathrm{H} 294$ & Round to orbicular & Round to obtuse & Sinuate & Obdeltate \\
\hline
\end{tabular}


petiole wing types namely obdeltate (11), linear (7) and obcordate (3) were observed in the hybrids (Table 1, Plate 4).

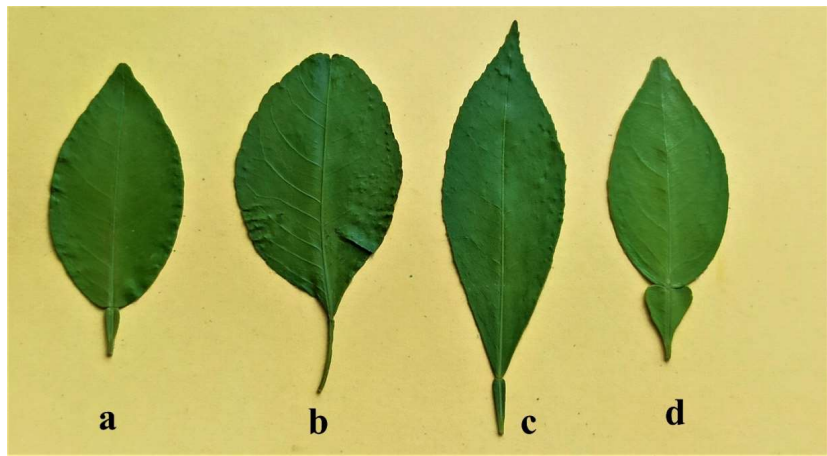

Plate 1. Hybrids displaying different leaf shapes. Ovate (a), Obovate (b), Lanceolate (c) and Elliptic (d)

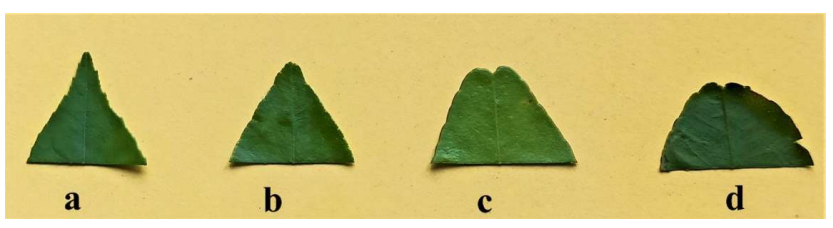

Plate 2. Illustration of different leaf apex of hybridsacuminate $(\mathbf{a})$, acute $(\mathbf{b})$, obtuse to retuse $(\mathbf{c})$ and retuse $(\mathbf{d})$

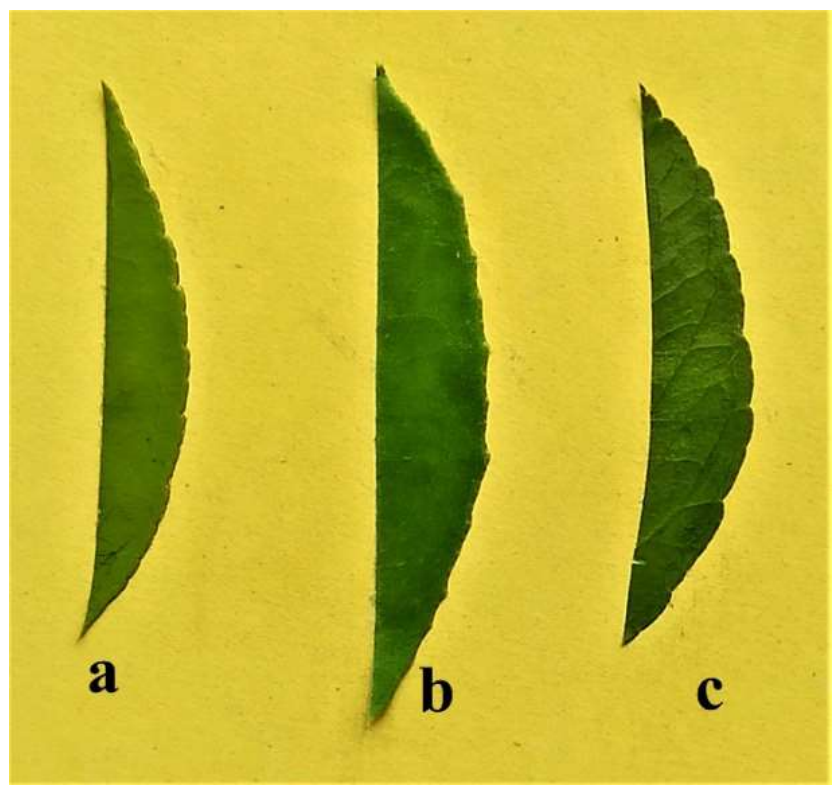

Plate 3. Illustration of the leaf margin types of hybridscrenate (a), dentate (b) and sinuate (c)

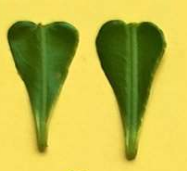

a

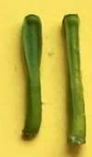

b

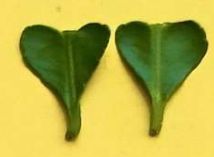

c
Plate 4. Illustration of petiole wing shapes of hybridsobdeltate (a), linear (b) and obcordate (c)
The leaf variables data was also used for drawing an Unweighted Neighbor Joining Tree. In the tree, the parents and hybrids became arranged into three major clusters (Fig. 1). The cluster- I contained 'Sour orange' and 13 hybrids and was further branched into three sub-clusters: IA, IB and IC with 5 ('Sour orange' and 4 hybrids), 5 and 4 hybrids. The cluster II contained two sub-clusters with 4 ('Jatti khatti' and three hybrids) and two hybrids, respectively. The cluster III contained three hybrids. Two of the hybrids in sub-cluster IB (H13-2 and H88-2) and IIA (H03-1 and $\mathrm{H} 90-1)$ were inseparable for the studied traits. Thus, the cluster analysis also revealed closeness of few hybrids to parent 'Jatti khatti', few to 'Sour orange' while the arrangement of remaining three hybrids into a separate cluster indicated the higher variability present in them over the two parents.

The appearance of higher magnitude of variation of leaf based traits in hybrid progeny than the parents indicates quantitative inheritance of the leaf traits (Iwata et al. 2002). Both of the parents come from a hybrid pedigree. 'Jatti khatti' ('Rough lemon') is a hybrid between acidic mandarin and citron

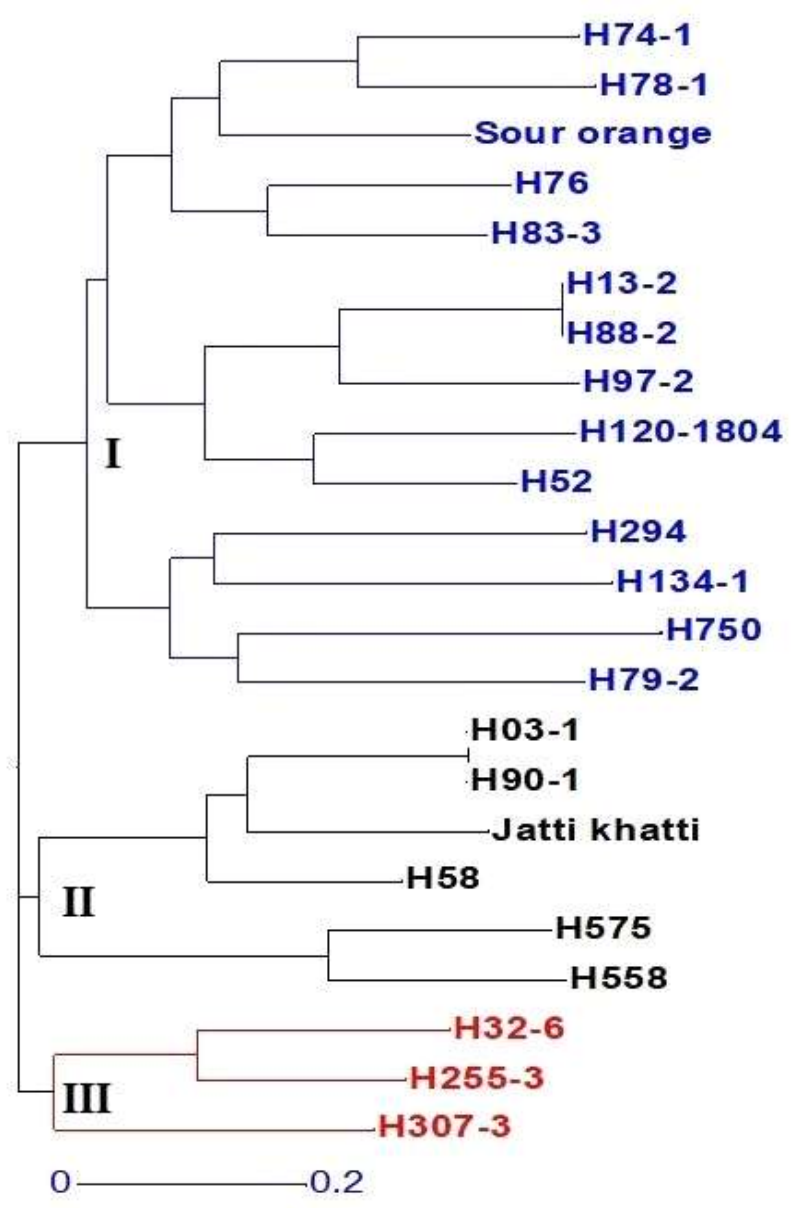

Fig. 1. Association of parents and hybrids as inferred through Unweighted Neighbour-Joining Tree in DARwin 6.0 
while 'Sour orange', is a natural hybrid of mandarin and pummelo (Nicolosi et al 2000, Curk et al 2015). Thus, the possibility of segregation and recombination in gametes during meiosis is very high. The emergence of shapes different from the parents might be a consequence of genetic recombination by virtue of crossing over between the homologues chromosomal segments during meiosis (Jiguang et al 1995)

The morphological features are important for the purpose of identification and conservation of germplasm. In citrus, leaf type (monofoliate, trifoliate and multifoliate) and broadness of petiole wing are two useful traits for distinguishing various citrus types at vegetative stage (Ballve et al 1997, Tan et al 2007). 'Sour orange' exhibit broad petiole wing (Ballve et al 1997, Kaur et al 2021). The shape of 'Sour orange' petiole wing in this study was found to be obdeltate. In this study, 11 hybrids ( $>50 \%$ ) had obdeltate type petiole wings. Thus, the shape of petiole wing can give a clue about the male parent pedigree of the hybrids.

Assessment of tolerance to Phytophthora nicotianae: After 48 hours of incubation of the leaf discs on Phytophthora culture, the reaction was observed in parents and hybrids. Phytophthora infection caused lesions on leaf discs and the response of the two parents was statistically different at $P \leq$ 0.05 . The susceptible parent 'Jatti khatti' exhibited leaf lesion size of $2.6 \mathrm{~cm}$ while in 'Sour orange', the lesion size was limited to $1.3 \mathrm{~cm}$ (Table 2). In response to Phytophthora infection, the hybrids responded differently. The H83-3 recorded lesion of size $(1.0 \mathrm{~cm})$ even statistically smaller than that of 'Sour orange'. The reaction of another six hybrids (H120-1804, H3-1, H97-2, H13-2, H134-1 and H307-3) for lesion size was statistically similar to the tolerant parent 'Sour orange', indicating that these hybrids possessed Phytophthora tolerance similar to 'Sour orange'. Another two hybrids (H558 and H79-2) developed lesion size of about 2.0 $\mathrm{cm}$, which might exhibit moderately tolerant response to the pathogen. Based on lesion size, three hybrids namely $\mathrm{H} 58$, $\mathrm{H} 88-2$ and $\mathrm{H} 575$ could be categorized as susceptible as their lesion size was equal to the susceptible parent 'Jatti khatti'. The response of the remaining nine hybrids was intermediate of moderately tolerant and susceptible categories of hybrids. Hence, these hybrids can be considered as moderately susceptible to Phytophthora (Table 2). The appearance of different sized leaf lesions in parents and also their differentiation into hybrids verified the utility of in vitro leaf inoculation method in authentically determining the Phytophthora tolerance in citrus. The leaf inoculation method is a quick and reliable method to identify the Phytophthora resistance (Harada and Kondo 2009). The results of differential susceptibility of parents using in vitro leaf inoculation method were in agreement with the findings of
Table 2. Size of Phytophthora induced leaf lesion in parents and 21 hybrids

\begin{tabular}{|c|c|}
\hline Plant ID & Lesion size on leaf discs $(\mathrm{cm})$ \\
\hline Jatti khatti (q) & $2.6 \pm 0.03^{a}$ \\
\hline Sour orange $\left({ }^{\Uparrow}\right)$ & $1.3 \pm 0.03^{g h}$ \\
\hline H83-3 & $1.0 \pm 0.03^{i}$ \\
\hline $\mathrm{H} 120-1804$ & $1.1 \pm 0.06^{\mathrm{hi}}$ \\
\hline H3-1 & $1.2 \pm 0.06^{\mathrm{hi}}$ \\
\hline H97-2 & $1.2 \pm 0.07^{\mathrm{hi}}$ \\
\hline $\mathrm{H} 13-2$ & $1.3 \pm 0.03^{\text {ghi }}$ \\
\hline H134-1 & $1.3 \pm 0.07^{\text {ghi }}$ \\
\hline H307-3 & $1.5 \pm 0.07^{9}$ \\
\hline H558 & $2.0 \pm 0.06^{f}$ \\
\hline $\mathrm{H} 79-2$ & $2.0 \pm 0.03^{\text {ef }}$ \\
\hline $\mathrm{H} 32-6$ & $2.2 \pm 0.03^{\text {def }}$ \\
\hline $\mathrm{H} 78-1$ & $2.2 \pm 0.03^{\text {def }}$ \\
\hline $\mathrm{H} 255-3$ & $2.2 \pm 0.07^{\text {def }}$ \\
\hline $\mathrm{H} 750$ & $2.2 \pm 0.07^{\text {def }}$ \\
\hline $\mathrm{H} 90-1$ & $2.2 \pm 0.07^{\text {def }}$ \\
\hline H52 & $2.3 \pm 0.03^{\text {cdef }}$ \\
\hline $\mathrm{H} 294$ & $2.3 \pm 0.06^{\text {bcde }}$ \\
\hline $\mathrm{H} 76$ & $2.3 \pm 0.06^{\text {bcde }}$ \\
\hline $\mathrm{H} 74-1$ & $2.3 \pm 0.07^{\text {bod }}$ \\
\hline H88-2 & $2.4 \pm 0.07^{\mathrm{abcd}}$ \\
\hline H575 & $2.5 \pm 0.03^{a b c}$ \\
\hline$\underline{\mathrm{H} 58}$ & $2.6 \pm 0.03^{\mathrm{ab}}$ \\
\hline
\end{tabular}

The \pm values represent standard error (SE). The genotypic means not sharing common superscript letters are statistically different as per Tukey's HSD test at $P \leq 0.05$

Dhakad et al (2014) that the reaction of genotypes to Phytophthora under leaf bait assays corroborated well with the results of seedling inoculation method. The result of the study has helped in preliminary determining the tolerance of 'Jatti khatti' ('Rough lemon') $\times$ 'Sour orange' hybrids to $P$. nicotianae. The tolerance of seven tolerant hybrids can be further verified by screening under natural field conditions followed by evaluating them for other stresses.

\section{CONCLUSIONS}

The hybrids displayed a great amount of variation for traits leaf lamina shape and leaf apex. The shape of petiole wing can help in demarcating the pedigree of more than $50 \%$ of the characterized hybrids. The verification of the Phytophthora tolerance of seven putatively tolerant hybrids under field conditions and their evaluation against other stresses could provide a rootstock that combines Phytophthora tolerance alongside the desirable features of 'Jatti khatti' (Rough lemon). 


\section{REFERENCES}

Anonymous 1999. Descriptors for Citrus. International Plant Genetic Resources Institute, Rome, Italy.

Ballve RML, Medina FHP and Bordingnon R 1997. Identification of reciprocal hybrids in citrus by the broadness of leaf petiole wing. Brazilian Journal of Genetics 20: 697-702.

Castellana S, Ranzino L and Beritognolo I 2020. Genetic characterization and molecular fingerprint of traditional Umbrian tomato (Solanum lycopersicum L.) landraces through SSR markers and application for varietal identification. Genetic Resources and Crop Evolution 21: 1-4.

Castle WS, Tucker DPH, Krezdorn AH and Youtsey CO 1993. Rootstocks for Florida. $2^{\text {nd }}$ Edition, University of Florida Cooperative Extension Publication. pp. 42.

Curk F, Ancillo G, Ollitrault F, Perrier X, Jacquemoud-Collet JP, Garcia-Lor A, Navarro L and Ollitrault P 2015. Nuclear speciesdiagnostic SNP markers mined from 454 amplicon sequencing reveal admixture genomic structure of modern citrus varieties. PLOS ONE 10(5):e0125628.

Dhakad UK, Kaur S and Thind SK 2014. Screening of citrus rootstocks and comparative analysis of different screening method against foot rot of kinnow mandarin. Bioscan 9: 13271331.

Harada $G$ and Kondo N 2009. Adzuki bean leaf infection by Phytophthora vignae f. sp. adzukicola and resistance evaluation using detached leaves inoculated with zoospores. Journal of General Plant Pathology 75(1): 52-55.

Iwata H, Nesumi H, Ninomiya S, Takano Y and Ukai Y 2002. Diallel analysis of leaf shape variation of citrus varieties based on elliptic. Breeding Science 52: 89-94.

Jiguang D, Qingwen H, Fengjun L, Hanping D and Xiuyan G 1995. A preliminary study on the trait segregation of one-year plum hybrid seedlings. Journal of Shenyang Agricultural University 4: 15-18.

Kaur K, Kumar K, Bhatia D, Naliath R, Likhar A, Arora PK and Singh K 2021. Allelic pattern of SSRs with high hybrid detection efficiency and inheritance of leaf petiole wing in interspecific Citrus crosses. Fruits 76(1): 30-38.

Kumar K, Gill MIS, Kaur H, Choudhary OP and Gosal SS 2010. In vitro mutagenesis and somaclonal variation assisted salt tolerance in rough lemon (Citrus jambhiri Lush.). European Journal of Horticultural Science 75(6): 233-238.

Lima RPM, Maximo HJ, Merfa MV, Dalio RJD, Cristofani-Yaly M and Machado MA 2018. Genetic tools and strategies for citrus breeding aiming at resistant rootstocks to gummosis disease. Tropical Plant Pathology 43(4): 279-288.

Nicolosi E, Deng ZN, Gentile A, La Malfa S, Continella G and Tribulato E 2000. Citrus phylogeny and genetic origin of important species as investigated by molecular markers. Theoretical and Applied Genetics 100: 1155-1166.

Perrier $X$ and Jacquemoud-Collet JP 2006. DARwin Software. http://darwin.cirad.fr/darwin.

Savita, Virk GS and Nagpal A 2012. Citrus diseases caused by Phytophthora species. GERF Bulletin of Biosciences 3(1): 1827.

Tan MJ, Song J and Deng S 2007. Production of mandarin $\times$ trifoliate orange hybrid population via embryo rescue with verification by SSR analysis. Euphytica 157: 155-160.

Vawdrey LL, Martin TM and De Fevari J 2005. A detached leaf bioassay to screen durian cultivars for susceptibility to Phytophthora palmivora. Australasian Plant Pathology 34: 251253. 